\title{
Current Trauma Care System in Saudi Arabia: Literature Review and a Proposed Action Plan
}

\author{
Abdallah Mohammad Alferdaus ${ }^{a, b} \quad$ Abdulaziz Shaher ${ }^{c}$ \\ aTrauma \& Acute Care Surgery Division, Department of Surgery, King Saud University Medical City, King Saud \\ University, Riyadh, Saudi Arabia; ${ }^{\text {b}}$ General Surgery Department, Khamees Mushayt General Hospital, Khamees \\ Mushayt, Saudi Arabia; 'Trauma \& Acute Care Surgery Division, Department of Surgery, Armed Forces Hospital of \\ the Southern Region, Khamees Mushayt, Saudi Arabia
}

\section{Keywords}

Trauma system · Injury prevention · Emergency medical services · Saudi Arabia

\begin{abstract}
Introduction: Trauma is one of the leading causes of morbidity and mortality in Saudi Arabia (SA) and worldwide and remains the leading cause of mortality in younger people. We conducted a literature review to assess the current trauma system in SA and formulated an action plan that might help guide leaders and colleagues in implementing a mature trauma system across the country. Methods: We searched PubMed, ScienceDirect, publications from the World Health Organization (WHO), and American College of Surgeons (ACS) and formal reports from the ministries and authorities in SA. Results: After aligning the trauma care system in SA to the WHO trauma system maturity index (TSMI) and ACS criteria for a mature system, the SA system was found to have many deficiencies in essential components such as national trauma registry or active trauma research activities. Injury prevention and prehospital care are progressing and may be graded as TSMI level III, indicating room for improvement. Regarding the definitive care at hospitals and centers, only 2
\end{abstract}

karger@karger.com www.karger.com/sjh

Karger"
(C) 2021 The Author(s)

Published by S. Karger AG, Basel

This is an Open Access article licensed under the Creative Commons Attribution-NonCommercial-4.0 International License (CC BY-NC) (http://www.karger.com/Services/OpenAccessLicense), applicable to the online version of the article only. Usage and distribution for commercial purposes requires written permission. centers at Riyadh met the criteria for level I trauma centers. Other regions in SA do not have major trauma centers yet. Overall, the components of the SA trauma care system were graded from levels I to III on the basis of the WHO TSMI and ACS criteria for a mature trauma system. Conclusion: In SA, injury remains the primary cause of death in children and other younger people. Efforts to reduce the prevalence and burden of trauma in SA are progressing. Completion of a nationwide trauma system would be a major step toward achieving that goal. We have proposed an action plan to achieve that goal.

(c) 2021 The Author(s).

Published by S. Karger AG, Basel

\section{Introduction}

Trauma is one of the leading causes of morbidity and mortality in Saudi Arabia (SA) and worldwide, and it remains the leading cause of mortality in younger people [1, 2]. In SA, road traffic crashes (RTCs) are the major cause of trauma-related death, with an estimated 16 deaths per day in 2019. Other trauma-related deaths are caused by falls, fights, assaults, drowning, and burns, along with other less likely causes such as suicide [3]. In 2016, there 
Table 1. Types of cases transferred to hospitals by the SRCA at each region in 2018

\begin{tabular}{|c|c|c|c|c|c|c|c|c|}
\hline Administrative region & road accidents & altercation & falls & burns & drowning & other accidents & diseases & total \\
\hline Makkah & 14,952 & 2,058 & 6,028 & 85 & 73 & 4,696 & 56,000 & 83,892 \\
\hline Medinah & 6,296 & 950 & 2,648 & 71 & 23 & 1,725 & 26,540 & 38,253 \\
\hline Qaseem & 3,568 & 366 & 1,031 & 37 & 24 & 800 & 10,380 & 16,206 \\
\hline Tabouk & 2,737 & 334 & 573 & 31 & 27 & 558 & 7,165 & 11,425 \\
\hline Ha'il & 2,180 & 306 & 464 & 15 & 7 & 370 & 4,970 & 8,312 \\
\hline Northern & 805 & 87 & 142 & 3 & 3 & 181 & 1,910 & 3,131 \\
\hline Jazan & 3,722 & 217 & 832 & 13 & 22 & 692 & 6,405 & 11,903 \\
\hline Najran & 1,389 & 171 & 237 & 10 & 3 & 406 & 2,391 & 4,607 \\
\hline Al-Bahah & 1,702 & 172 & 399 & 2 & 12 & 234 & 3,455 & 5,976 \\
\hline
\end{tabular}

SRCA, Saudi Red Crescent Authority.

were 44,783 inhospital deaths from all causes, and 6,460 (14.4\%) were related to trauma [3]. In 2018, approximately 112,142 (307 per day) injured patients were transferred to hospital by the Saudi Red Crescent Authority (SRCA), which is the main emergency medical service (EMS) for prehospital care and transfer in SA (Table 1) [4].

The socioeconomic cost including depletion of young human resources, emotional and psychological effects on families, strain on health-care facilities, and economic sequelae of trauma is another major concern of injuries in SA [5]. It is estimated that the economic impact of RTC alone is $>22,000$ million Saudi Riyals every year $(>5.85$ billion US dollars) $[6,7]$.

Implementation of a nationwide trauma system has led to decreases in mortality and morbidity among traumatized patients in many developed countries [8-17]. The World Health Organization (WHO) trauma system maturity index (TSMI) was developed to help health leaders assess trauma systems. The TSMI has 4 assessment elements that include prehospital trauma care, education, training, facility-based trauma care, and quality assurance (Table 2) with 4 recognized levels ranging from level I for the least mature systems to level IV for fully mature systems. The American College of Surgeons (ACS) published the Resources for Optimal Care of the Injured Patient (6th edition) in 2014 with the aim of helping leaders assess the trauma system in their states or countries for continuous improvement. A comprehensive trauma system encompasses components related to trauma preven- tion, prehospital care, hospital care, rehabilitation, education and training of human resources, a trauma registry, system evaluation, performance improvement, and research [18].

Al-Naami et al. [6] and Alharbi et al. [19] reviewed the trauma system in SA. However, the present extensive review may provide additional information useful for recognizing the burden of trauma in SA. Particularly, this review explains in detail the authorities' efforts in the last few years to lessen the burden of trauma. We also propose an action plan for completion of a nationwide trauma system. The purpose of this literature review was to address 3 objectives: first, to assess and describe the burden of trauma in SA; second, to review the efforts taken by the ministries and authorities to lessen that burden and the efforts taken to implement a nationwide trauma system; and third, to propose an approach that might hasten completion of a nationwide mature trauma system in SA within the next few years.

\section{Methods}

In SA, no formal trauma registry exists for collection and analysis of data. We collected data from official Arabic reports on websites of the Ministry of Health ( $\mathrm{MOH})$, the general authority for statistics, which is a government-maintained authority, and the SRCA. The inclusion criteria of the Arabic reports were that they were uploaded on websites between 2016 and 2020 and focused on the burden of trauma and trauma care. The total number of 
Table 2. WHO TSMI

\begin{tabular}{|c|c|c|c|c|}
\hline & Level I & Level II & Level III & Level IV \\
\hline $\begin{array}{l}\text { Prehospital } \\
\text { trauma care }\end{array}$ & $\begin{array}{l}\text { No mapping of } \\
\text { prehospital resources, No } \\
\text { formal EMS, unavailability } \\
\text { or duplication of } \\
\text { prehospital services, no } \\
\text { defined communication } \\
\text { system }\end{array}$ & $\begin{array}{l}\text { Prehospital resources are } \\
\text { identifiable, no } \\
\text { coordination between } \\
\text { public and private } \\
\text { providers of prehospital } \\
\text { care, no universal access } \\
\text { number, weak links of } \\
\text { communication }\end{array}$ & $\begin{array}{l}\text { Formal EMS present, universal } \\
\text { access number available, } \\
\text { coordination seen between } \\
\text { various agencies for prehospital } \\
\text { care delivery and well-defined } \\
\text { communication }\end{array}$ & $\begin{array}{l}\text { Formal EMS controlled by } \\
\text { a lead agency, national } \\
\text { universal access number, } \\
\text { legislative mechanism in } \\
\text { place to govern EMS and } \\
\text { allow universal coverage }\end{array}$ \\
\hline $\begin{array}{l}\text { Education } \\
\text { and training }\end{array}$ & $\begin{array}{l}\text { No identified health } \\
\text { personnel to offer } \\
\text { primary trauma care in } \\
\text { community }\end{array}$ & $\begin{array}{l}\text { Identified health } \\
\text { personnel in the } \\
\text { community for } \\
\text { emergency trauma care; } \\
\text { no definite training } \\
\text { requirement for health } \\
\text { workers or ambulance } \\
\text { personnel }\end{array}$ & $\begin{array}{l}\text { Health professionals and } \\
\text { paramedics are trained in } \\
\text { provision of emergency trauma } \\
\text { care; training courses are } \\
\text { available for trauma education }\end{array}$ & $\begin{array}{l}\text { Educational standards and } \\
\text { training for emergency } \\
\text { trauma care providers laid } \\
\text { down; licensing and } \\
\text { renewal norms for } \\
\text { different levels of } \\
\text { paramedics are in place }\end{array}$ \\
\hline $\begin{array}{l}\text { Facility- } \\
\text { based } \\
\text { trauma care }\end{array}$ & $\begin{array}{l}\text { Role of secondary and } \\
\text { tertiary facilities unclear, } \\
\text { health facilities lack } \\
\text { human and physical } \\
\text { resources, and no clear } \\
\text { referral linkages }\end{array}$ & $\begin{array}{l}\text { Roles of various health- } \\
\text { care facilities are clear, } \\
\text { referral linkages are } \\
\text { present, no } \\
\text { documentation or needs } \\
\text { assessment of facilities in } \\
\text { line with EsTC, and no } \\
\text { lead agency in the system }\end{array}$ & $\begin{array}{l}\text { Health facilities in the systems } \\
\text { are assessed in line with EsTC } \\
\text { guidelines and documented } \\
\text { human and physical resources } \\
\text { are available and ensured round } \\
\text { the clock; lead agency present }\end{array}$ & $\begin{array}{l}\text { Mechanism of hospital } \\
\text { verification and } \\
\text { accreditation is in place } \\
\text { through } \mathrm{MOH} \text { or } \\
\text { professional bodies; lead } \\
\text { agency established with } \\
\text { mandate to supervise } \\
\text { trauma care }\end{array}$ \\
\hline $\begin{array}{l}\text { Quality } \\
\text { assurance }\end{array}$ & $\begin{array}{l}\text { No injury surveillance or } \\
\text { registry mechanism in } \\
\text { place to get } \\
\text { comprehensive data }\end{array}$ & $\begin{array}{l}\text { Injury data available, but } \\
\text { no formal attempts to } \\
\text { document and analyze } \\
\text { the data, and no initiative } \\
\text { for Q/A program }\end{array}$ & $\begin{array}{l}\text { Basic Q/A programs in line with } \\
\text { EsTC guidelines are in place }\end{array}$ & $\begin{array}{l}\text { Formal Q/A programs are } \\
\text { in place and are mandated } \\
\text { in prehospital and facility- } \\
\text { based services }\end{array}$ \\
\hline
\end{tabular}

EsTC, Essential Trauma Care Project; EMS, Emergency Medical Services; MOH, Ministry of Health; Q/A, Quality Assurance; WHO, World Health Organization; TSMI, trauma system maturity index.

included Arabic reports was $11[3,4,20,21]$. The 2 authors, A.M.A. and A.S., independently performed the collection and retrieval of relevant reports and then screened the retrieved reports together. We then searched the PubMed and ScienceDirect literature databases for reports in English by using the following keywords: "trauma system" OR "injury prevention" OR "emergency medical services" AND SA. The inclusion criteria of the articles were availability of the full text and that the texts focused on the burden of trauma, injury prevention, prehospital trauma care, trauma education and training, and the trauma care system in SA. The published literature on the subject was scarce, and only a total of 27 articles were collected by A.M.A. and A.S. independently from each other (Fig. 1). Those 27 articles were screened by reading the abstracts first by the 2 authors together, and 7 were excluded. The remaining 20 articles were thoroughly screened by A.M.A. and A.S. After inclusion and exclusion of the fully screened articles in this review, only 10 scientific articles were included ( $\mathrm{Ta}$ ble 3).

Current Trauma Care System in Saudi Arabia
The final 10 articles and the 11 governmental reports were used to describe the current state of the trauma care system in SA (total of 21 reports). We then compared the findings against the criteria set in the TSMI by the WHO for mature trauma systems (Table 2) and against the criteria in the quick reference guide provided by the ACS in the Resources for Optimal Care of the Injured Patient (6th Edition) in its last chapter [18]. Finally, we formulated a proposed action plan based on the experiences from countries with mature trauma systems.

\section{Results}

Our search identified 38 reports and articles. After records screening, 17 were excluded, and a total of 21 formal government reports and scientific articles were included in the review (Fig. 1; Table 3). The current com- 
Fig. 1. Methods of searching articles in PubMed and ScienceDirect sites and formal reports from ministries and general authorities in SA. SA, Saudi Arabia.

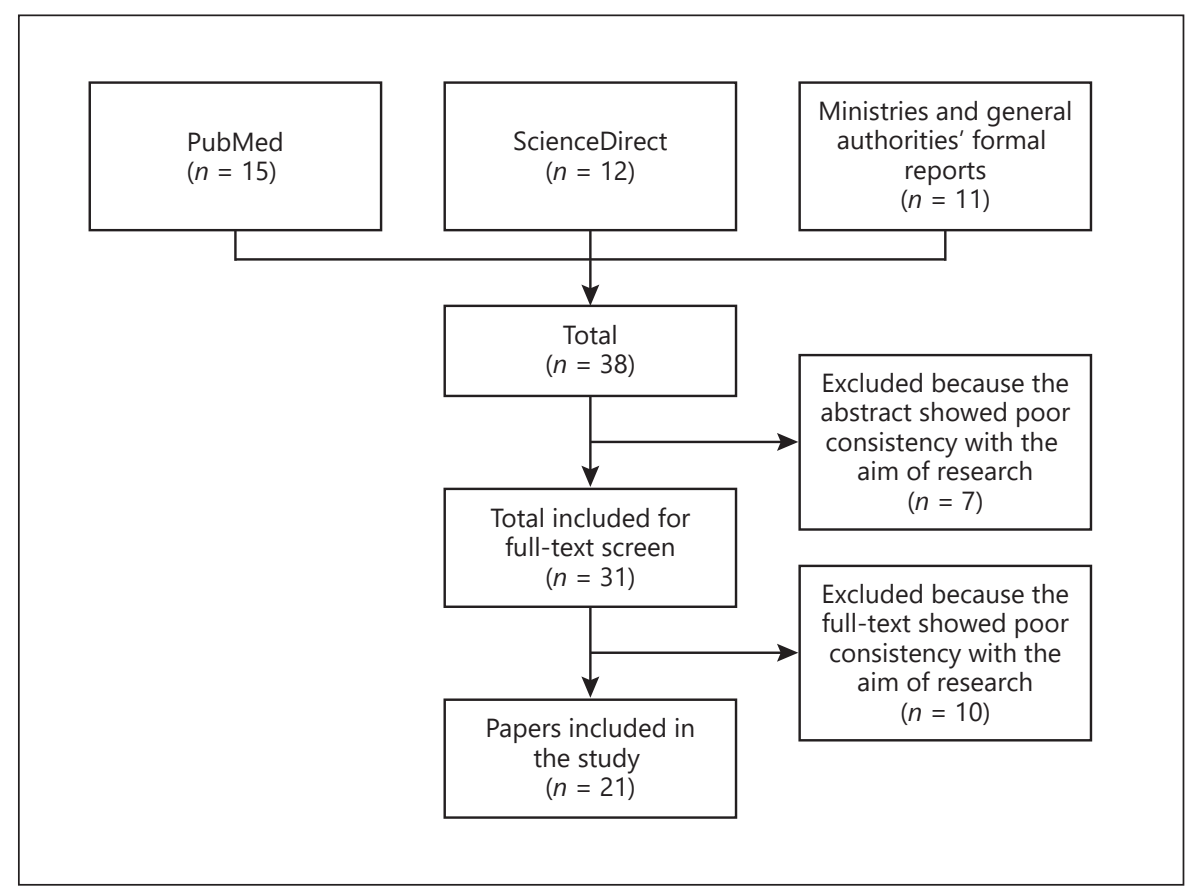

Table 3. Summary of the scientific articles included in the review

\begin{tabular}{lll}
\hline Study & Design & Goal \\
\hline Alharbi et al. [19] & Descriptive study & Evaluation of current trauma system in SA \\
Al-Naami et al. [6] & Descriptive study & Effort to implement a trauma system \\
Ford et al. [31] & Descriptive study & Effort to implement a trauma registry \\
Al-Ghamdi et al. [25] & Prospective observational & Evaluation of current EMS in Riyadh \\
Alghnam et al. [22] & Retrospective & Inhospital mortality among RTA patients \\
Alghnam et al. [28] & Retrospective & Burden of traumatic injuries \\
Alghnam et al. [23] & Retrospective & Inhospital mortality and implementation of a camera ticketing system \\
Alharbi et al. [29] & Prospective observational & Evaluation of inhospital mortality among RTA patients \\
Alanazi et al. [30] & Review study & Effort to implement an electronic national injury surveillance system \\
Ansari et al. [5] & Review study & Evaluation of causes and effects of RTA in SA \\
\hline
\end{tabular}

SA, Saudi Arabia; EMS, emergency medical service.

ponents of the SA trauma system comprising injury prevention, prehospital care, hospital care with education and training of human resources, rehabilitation, trauma registry, research, system evaluation, and performance improvement are described and discussed and then compared with the WHO trauma system classifications and the ACS ideal trauma system elements.

\section{Injury Prevention}

Prevention is considered by some experts to be the most important part of a trauma system. The science of injury prevention has many roots, such as in public health, medicine, criminology, and engineering. Dr. William Haddon in 1970 was the first to develop an approach to injury prevention. He developed 10 injury countermeasures in the 3 phases of injury: pre-, during, and postinjury. These countermeasures enabled researchers to develop a plan to reduce the incidence and consequences of injury. Those 10 countermeasures are currently included within the 3 main measures: primary prevention that seeks to avert injuries by altering exposure, secondary prevention that seeks to detect injuries early and treat 
them, and tertiary prevention that seeks to limit disability or to rehabilitate [6].

Although the trauma system is rooted in secondary and tertiary prevention, primary prevention is the most efficient measure for lessening the burden of injury [22]. In 2010, the government of SA implemented a program to decrease and control speeding while driving vehicles by implementing a camera-ticketing system [23]. The monitoring system was extended in 2018 to detect and control nonadherence to seatbelt wearing, the use of phones by hand while driving, and driving through red lights at traffic intersections in all regions. Those efforts have resulted in a decrease in RTC in SA from 1,645 accidents/100,000 population in 2016 to 1,102 accidents/100,000 population in 2019 (33\% reduction), with a decrease in RTC-related death from 28.8 death/100,000 population in 2016 to 16.8 death/100,000 population in 2019 (41\% reduction) [3].

In 2009, the Ministry of the Interior (MOI) located socalled black spots with the highest incidences of RTCs. Four main roads were identified, and corrective steps were implemented, including roadway maintenance, reducing maximum speed limits in those black spots, and collecting more information about violations from the camera-ticketing system, as described earlier [23]. The effect of these efforts in the identified black spots has not been well-studied, so this might be an important area for future studies.

According to the ACS [18], the trauma centers' leaders and physicians have a major role in injury prevention programs through community education and by helping to shape the policy decisions. As per Ansari et al. [5], many programs and campaigns have failed to re-educate drivers probably because they were targeting the wrong audience. Additionally, as discussed by Ansari et al. [5], attention should be directed toward young people before they can drive to encourage positive behavioral changes. Assessing the effects of community education efforts might also be an important area of future studies.

\section{Prehospital Care}

Significant variation was found across prehospital trauma systems based on the volume of trauma incidents, availability of resources, availability of organized response from EMS, and demography. The prehospital system in SA is regulated by government ministries and authorities [24]. The ministries include the Ministry of Transport and Logistic Services, MOH, MOI, Ministry of Commerce, Ministry of Municipal Rural Affairs and Housing, Ministry of Education, Ministry of Media, and
Ministry of Communications and Information Technology. The authorities include the Transport General Authority; Saudi Standards, Metrology, and Quality Organization; and the SRCA, with supervision by the Traffic Safety Ministerial Committee. The SRCA provides free prehospital care for the public as well as contributes to humanitarian relief outside the country $[19,21]$. The SRCA offers medical services for first aid and transportation of ill citizens and expatriates in SA. Along with its participation in delivery of relief aid to crisis victims outside of SA, the SRCA also encourages individuals, especially youth, to volunteer in its activities, and it also has training programs for its personnel and for society. The SRCA is fully funded by the government of SA and provides free services to the population. EMS rescue times in Riyadh were assessed in 2001 by Al-Ghamdi [25]. He found that the average total rescue time, including response time, scene time, and transport time, was 35.84 min and concluded that there is room for improvement in the rescue time in Riyadh. The SRCA in 2020 increased their efforts and services to increase the number of ambulance centers to 486 across the country and 1,379 fully equipped ambulances (Table 4). In 2018, the SRCA provided services for 568,682 calls; of them, 72,013 were RTC-related injuries, 21,312 were fall-related injuries, 11,907 were assault-related injuries, and 7,938 were pedestrian injuries (Table 1). The level of care provided by the SRCA is generally provided by 2 main levels of EMS personnel: paramedics who have advanced life-support skills and emergency medical technicians who have only basic life-support skills and provide services $24 \mathrm{~h}$ a day in all centers [4].

The SRCA receives calls through a universal access phone number and has improved their system for announcements and their communication with the leading health sectors, $\mathrm{MOH}$ divisions, and hospitals. In 2020, the SRCA promoted a smart-phone application named As'efny in Arabic (Rescue Me in English) that aims to decrease the response time for injuries and provide advanced communication and supervision. This application is available in 9 languages to serve as many potential beneficiaries as possible across the country. The beneficiaries of this free application can send notifications for others and SOS signals from their own locations too. The SRCA also launched an electronic system in 2020 that had 25 major goals, such as registering announcements, helping to delineate the shortest route to an injury location, helping to communicate with hospitals and ER personnel for preparation, and helping to register injured patients' data electronically [21]. 
Table 4. SRCA centers and ambulances distributed among the 13 regions with the number of cases serviced

\begin{tabular}{|c|c|c|c|c|c|}
\hline Administrative region & $\begin{array}{l}\text { Cases managed by the } \\
\text { SRCA and transferred to } \\
\text { hospitals (2018), } n\end{array}$ & centers (2021) & $\begin{array}{l}\text { average cases per } \\
\text { center (2018) }\end{array}$ & $\begin{array}{l}\text { ambulances } \\
(2021)\end{array}$ & $\begin{array}{l}\text { average cases per } \\
\text { ambulance (2018) }\end{array}$ \\
\hline Riyadh & 62,382 & 108 & 686 & 310 & 258 \\
\hline Makkah & 83,892 & 94 & 999 & 259 & 392 \\
\hline Medinah & 38,253 & 35 & 1,195 & 101 & 450 \\
\hline Aseer & 22,125 & 39 & 632 & 107 & 249 \\
\hline Tabouk & 11,425 & 26 & 497 & 53 & 279 \\
\hline Ha'il & 8,312 & 15 & 594 & 51 & 213 \\
\hline Northern & 3,131 & 13 & 261 & 45 & 76 \\
\hline Jazan & 11,903 & 21 & 626 & 52 & 243 \\
\hline Najran & 4,607 & 15 & 307 & 50 & 102 \\
\hline
\end{tabular}

SRCA, Saudi Red Crescent Authority.

Filed triage identifies severely injured patients at the scene and triggers the decision to transport the most severely injured to a nearby hospital capable of treating those injuries. According to Alharbi et al. [19], there are no clear written guidelines yet for field triage or trauma destination protocols. Field triage, trauma destination protocols, and trauma bypass at the direction of physicians and surgeons are expected to improve after implementation of the previously mentioned electronic prehospital system in 2020 with 25 major goals. Future assessments are needed to achieve this goal. According to the WHO TSMI tool, the prehospital trauma care in SA would be classified as levels III to IV, indicating room to improve the system, especially for level IV (Tables 2, 5).

\section{Hospital Care}

In 2018, SA had approximately 494 hospitals that provided services for the population in 13 regions. Among those 494 hospitals, 284 were MOH hospitals, 47 were for other governmental sectors, and 163 were for the private sector. Among those 284 hospitals managed and directed by the $\mathrm{MOH}$, there are 224 general hospitals with different capabilities, 17 for obstetrics/gynecology and pediatrics, 3 exclusively for obstetrics/gynecology, 3 exclusively for pediatrics, 2 for rehabilitation, and 35 for other specialties [4].

There are only 2 trauma centers in SA: the King Saud Medical City (KSMC), which is managed and directed by the MOH, and the King Abdulaziz Medical City (KAMC) that is under the care of another governmental sector, the National Guard. Both trauma centers are in Riyadh. These 2 centers are equipped with $>1,000$ beds and serve their patients with advanced subspecialized personnel in addition to serving as training centers for specialty programs and fellowships.

In 2018, there were a total of 43,680 beds in the 284 $\mathrm{MOH}$ hospitals, of which 2,538 beds were intensive care units [4], with a capacity increase in 2020 to $>6,000$ intensive care unit beds due to the COVID-19 pandemic. Recently, the Saudi Central Board for Accreditation of Healthcare Institutions (CBAHI) agreed to develop a future program to acknowledge and accredit the trauma centers and units in SA [26].

The postgraduate training programs are governed and led by the Saudi Commission for Health Specialties (SCFHS) and now include $>1,832$ training programs and $>20,675$ trainees in different specialties and in 3 countries [27]. Interfacility critical care transportation policy is already set and led by the $\mathrm{MOH}$, but roles of some healthcare facilities remain unclear. $\mathrm{MOH}$ interfacility transfer is graded to 3 levels based on the referring facility treating physicians or surgeons. Those levels are lifesaving transfer, emergency $(<24 \mathrm{~h})$ transfer, and nonemergency transfer. The referring facility will communicate through a unified referring system with the transfer commanders at the level of $\mathrm{MOH}$ who work around the clock and special- 
Table 5. WHO TSMI tested against the current trauma care system in SA

\begin{tabular}{|c|c|c|}
\hline Level of prehospital trauma care & III/IV & $\begin{array}{l}\text { Formal EMS present and controlled by SRCA } \\
\text { National universal access number available } \\
\text { Coordination seen between various agencies for prehospital care delivery }\end{array}$ \\
\hline Education and training & III/IV & $\begin{array}{l}\text { Health professionals (inclusive of nurses and therapists), and paramedics are trained } \\
\text { in provision of emergency trauma care } \\
\text { Training courses are available for trauma education } \\
\text { Educational standards and training for emergency trauma care providers laid down } \\
\text { Licensing and renewal norms for different levels of health professionals are in place }\end{array}$ \\
\hline Level of facility-based trauma care & $\mathrm{I} / \mathrm{II} / \mathrm{III}$ & $\begin{array}{l}\text { Role of secondary and tertiary facilities unclear } \\
\text { Referral linkages are present } \\
\text { Physical resources are available and ensured round the clock }\end{array}$ \\
\hline
\end{tabular}

SA, Saudi Arabia; EMS, emergency medical services; SRCA, Saudi Red Crescent Authority; TSMI, Trauma System Maturity Index; WHO, World Health Organization.

ize in emergency medicine or surgery. After acceptance of a transfer, the SRCA then transfers the injured patient to an appropriate facility. The SRCA is equipped with 14 helicopters and fixed-wing aircraft for this purpose and for other humanitarian relief purposes [21].

A study by Alghnam et al. [28] found that patients who are severely injured following RTCs in SA, after adjusting for age, sex, Triage-Revised Scale (T-RTS), Injury Severity Score (ISS), mechanism of injury, hypotension, surgery, and head injuries, were significantly more likely to die in the hospital than comparable patients admitted to large US trauma centers. This article and another article by Alharbi et al. [29] suggest that inhospital care for trauma patients in SA, even in level I centers, could be improved. On the basis of the conclusions of those 2 articles and according to the WHO TSMI tool, the interhospital trauma care in SA would be classified between levels I and III, indicating the need for major efforts for improvement (Tables 2, 5).

\section{Rehabilitation}

According to the statistics in 2018 [4], there are only 2 rehabilitation centers across the country. Other facilities provide the rehabilitation care as an inhospital care. The 2 fully equipped rehabilitation centers are the Medical Rehabilitation Hospital in Riyadh and the rehabilitation hospital in the Madinah region. Both hospitals are governed by the $\mathrm{MOH}$. The Medical Rehabilitation Hospital was the first accredited hospital by commission on accreditation of rehabilitation facilities outside of North America. Both centers provide specialized services of physiotherapy, occupational therapy, artificial limbs and compensative devices, speech therapy, and rehabilitation therapy. Other facilities provide mainly the physiotherapy care alone. Only 194 hospitals governed by $\mathrm{MOH}$ provide physiotherapy care, and only 33 hospitals provide the occupational therapy care, whereas 21 hospitals provide artificial limbs services and 7 for speech therapy $[3,4]$.

There is no registry to assess the rehabilitation care or the long outcome of discharged injured patients in SA. As set by the ACS, rehabilitation care should be provided by either a free-standing hospital or interhospital rehabilitation services. Brain-injured patients should be cared early in their course of admission by a neuropsychology team. Other teams might include physical therapy team for musculoskeletal injury and for all intubated patients from their first day of admission to maintain joint flexibility and muscle strength, speech, and swallowing team along with a social workers team [18]. Data for the rehabilitation services efforts are sparse, and there is no wellrecognized universal nationwide protocol for rehabilitation of the injured patient in SA.

\section{Trauma Registry}

Only 2 centers across the country have a designed trauma registry [30]. Those 2 hospitals are the 2 hospitals 
mentioned ahead (KAMC and KSMC). In 2014, Alghnam et al. [22] at KAMC assessed the challenges and potential opportunities to improve trauma data collection and research in SA. The trauma registry system at KAMC was initiated in 2001. Their data entry has 2 steps. First, a nurse completes a structured checklist to gather demographic, anatomic, physiological, and other variables. Second, a trained research coordinator ensures that data are complete and enters the information into the registry using "Microsoft Access software 2000." Data collection sheet at KAMC was designed to mirror trauma registries in North America hospitals. Additionally, the registry at the KAMC includes measuring scores like the Glasgow Coma Scale, the ISS, and the T-RTS. Alghnam et al. [22] also mentioned some restrictions and limitations in the KAMC's registry. Some missing values with traffic-related data (e.g., seatbelt use) were significantly higher at the KAMC than at centers in the UK and USA. The higher frequency of missing data at the KAMC could have several reasons. The language barrier between the nurse filling the data collection sheet and patients could be 1 reason. Additionally, some information was originally collected at the prehospital setting by the police and the SRCA and not by the nurse or the coordinator at the hospital. A third reason is the limited knowledge on longterm outcomes, such as permanent disability and quality of life.

In 2020, Ford et al. [31] described a novel 12-step implementation plan that was commenced in 2017 for trauma registry launch at the KSMC. Based on the ACS, trauma registry data must be collected and analyzed by every trauma center. Data then should be aggregated and analyzed by the agency that directs the trauma system at the city, county, or state level. Finally, data must be submitted every year in a timely fashion so that they can be aggregated and analyzed at the national level [18].

The exact inclusion and exclusion criteria used to select patients for entry into a trauma registry vary across hospitals in the USA. Some trauma centers, trauma systems, and state agencies modify the inclusion and exclusion criteria to address the specific needs of their patient populations. Although some centers in the USA have designed their own computerized registries, these efforts are no longer necessary according to the ACS. Several effective trauma registry software packages are commercially available. These programs are designed to run on personal computers or hospital computer systems [18].
Research, System Evaluation, and Performance Improvement

It is not an overstatement to say that research is the core of trauma care systems. Research drives the system and provides the foundation for system development and performance improvement [6]. In SA, trauma research is sparse and is mostly attributed to the lack of a trauma registry.

For system evaluation and performance improvement, rules and protocols should be set by each major trauma center in each region, and those rules should be monitored for application [32]. Examples of such protocols might include trauma team activation criteria, a massive transfusion protocol, management of severe traumatic brain injury, and VTE prophylaxis. Any adverse event should be addressed and reviewed for opportunities for improvement, for example, delay in operation room availability or turnaround time for the massive transfusion protocol.

System evaluation and performance improvement per the ACS must be supported by the trauma registry, which is still lacking in SA. Trauma leaders at each major trauma center can return to chapter 16 in the Resources for Optimal Care of the Injured Patient (6th edition) in 2014 [18] for optimal applications for reviewing and monitoring the application and outcomes by the quality departments and hospital leaders and to take corrective actions. Data about the presence of a mature system evaluation and performance improvement at each center in SA are lacking. Following the WHO TSMI guidelines, performance improvement or quality assurance would be level I to II, indicating that major efforts are needed to advance to a higher level (Tables 2, 5).

\section{Discussion}

Many of the rules set by the WHO and ACS for an effective trauma system were not present in multiple studies of the trauma system in SA. The presence of a mature trauma system in many developed countries has led to a far better outcome in injured patients [33-36]. Our main goal therefore was to assess the current trauma care system in SA and propose a novel roadmap for hastening further development and improvement of the trauma system in SA. Our roadmap comprises 5 major steps with subsidiary steps (Table 6): trauma registry implementation; trauma interhospital care amendment; trauma prehospital care refinement; trauma rehabilitation care; and system evaluation, performance improvement, and research. 
Table 6. Novel roadmap for implementation of a trauma system in SA

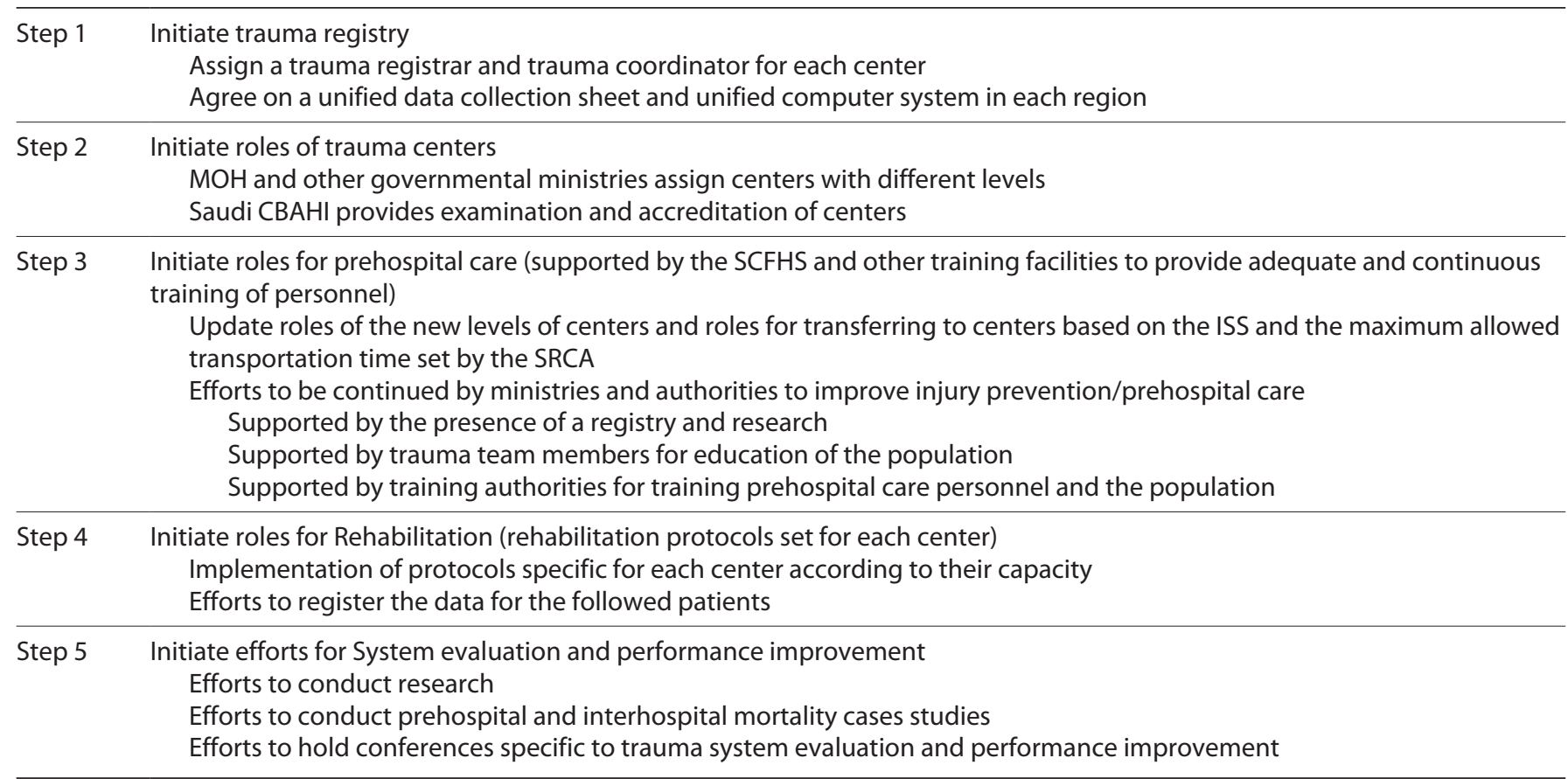

$\mathrm{MOH}$, Ministry of Health; CBAHI, Central Board for Accreditation of Healthcare Institutions; SCFHS, Saudi Commission for Health Specialties; ISS, Injury Severity Score; SRCA, Saudi Red Crescent Authority; SA, Saudi Arabia.

The first step comprises the steps already taken by the KAMC and KSMC years ago. An order to assign a trauma registrar and a trauma coordinator at each hospital in SA should be sent from the highest level of the health authorities in each region. Regions should agree therefore on unified forms of data collection with unified inclusion criteria and to enter them in a unified computer system. Collaboration between prehospital personnel and the trauma registrar is of utmost important. Prehospital personnel should complete their unified forms for trauma victims and submit a copy to the receiving hospital, as already required by the SRCA. The National Trauma Data System Data Dictionary (2021) from the ACS contains in its first 4 pages the data that should be considered for entry into the data collection sheet, and it is available as a PDF file at their site [37].

The second important step is the trauma interhospital care amendment. In the USA, $69 \%-84 \%$ of the population have access to a level I or level II trauma centers within 45-60 min. Approximately 46 million Americans have no access to a level I or II trauma center within an hour. An approximately equal number of Americans, 42.8 million, have access to 20 or more level I or II trauma centers

Current Trauma Care System in Saudi Arabia within an hour [34]. That data suggest that geospatial planning for optimal placement of new trauma centers should be studied thoroughly by the leaders before assigning hospitals as trauma centers [38-40]. In the USA also, states with poor trauma center access $(>1 \mathrm{~h})$ have more prehospital deaths than states with faster trauma center access [35]. The statewide system of trauma care in Victoria, Australia, is considered a role model for trauma care systems [36]. Australia began implementation of the system in 2000 and completed it in 2003. Victoria comprises $227,444 \mathrm{~km}^{2}$ of land, with a population of $6.6 \mathrm{mil}-$ lion. About $70 \%$ of the population resides in Melbourne, the capital, and $90 \%$ of the population lives in urban areas. About $30 \%$ of the population is $<20$ years of age. The state has 2 level I adult trauma centers and one level I pediatric center. There are 8 level II trauma centers in the capital and 10 level II centers out of the capital, and 117 other centers have been assigned roles within the system. Any severely injured patients within $30 \mathrm{~min}$ of a level I trauma center will be transferred to it; otherwise, the patients go to the nearest level II hospitals. The land area is 9.5 times larger in SA than in Victoria, and the population is $>5.3$ times larger. In 2018, there were 494 hospitals, including 
Table 7. Levels of trauma centers and the roles for each level

\begin{tabular}{ll}
\hline Level & Role \\
\hline Level I & Subspecialized interventions are available \\
Level II & Surgeons of different specialties, ICUs are available \\
Level III & Emergency surgery is available then transfer \\
Level IV & ATLS care and no surgeries \\
\hline
\end{tabular}

ICU, intensive care unit.

major private hospitals, in SA, with 2,390 primary healthcare centers [4]. Table 7 shows the levels of trauma centers and the role of each level. We believe therefore that some of the primary health-care centers can be designated as needed along with some small hospitals as level IV centers, and $>150$ hospitals can be designated and prepared to be level I and II centers ( $>7$ times as many level I and II center than in Victoria).

The third step concerns prevention and prehospital care. These efforts are led by the national transformation program that includes 5 ministries and 3 registered committees. The efforts from 2016 to 2019 have resulted in a decrease in RTC-related deaths to $41 \%$ (from 28.8 deaths/100,000 population in 2016 to 16.8 deaths/100,000 population in 2019), where the actual target was 20 deaths/100,000 population in 2020 , which indicates some success. More efforts are already running to reach levels comparable to those of Europe (9.3 deaths/100,000 population) within the next few years. The SRCA has increased its centers from 439 in 2018 to 486 in 2020 and its ambulances from 1,153 in 2018 to 1,379 in 2020. Training of prehospital personnel is run by the SCFHS, SRCA, and other training authorities by agreement with the ACS. The presence of a registry and ongoing research is of paramount importance to further improve trauma prevention efforts and prehospital care. Injury prevention is also the responsibility of all trauma team members. According to the ACS, each trauma center must have someone in a leadership position who has injury prevention as part of his or her job description. Further, any trauma team member who can speak effectively should embrace the media and target the audience to motivate and prepare them for changing their risk-taking behavior [18].

The fourth step recommends that centers should have a registry to follow patients for rehabilitation. We believe that center leaders should do that by implementing protocols specific to each center according to their capacity, with emphasis on registering the data for the patients they follow.
The fifth step recommends that trauma center leaders, with the collaboration of the concerned departments in the center (surgery, emergency, anesthesia, quality, and others) and prehospital centers (the SRCA), should periodically evaluate improvement in performance by conducting case studies and mortality meetings and present the lessons learned in quality or trauma conferences annually to improve the trauma system. Table 7 summarizes the proposed action plan.

One limitation of this review was the inability to review and assess all elements of a mature trauma system, such as disaster preparedness. Another limitation was that the WHO TSMI does not cover all parts of a mature system, so some relevant important information was missed in the TSMI.

\section{Conclusion}

Implementing a mature trauma system was found to be associated with reduced mortality and morbidity. In SA, the infrastructure to build a nationwide trauma system is ready. A registry system, ongoing research, and continuous education and training are vital for any mature trauma system. Further collaboration is needed between ministries and authorities to achieve this important nationwide goal.

\section{Conflict of Interest Statement}

The authors have no conflicts of interest to declare.

\section{Funding Sources}

This study did not receive any funding.

\section{Author Contributions}

The first draft was prepared initially by A.M.A. and was revised with critical comments from A.S. Both authors read and approved the final manuscript. 


\section{References}

1 Rhee P, Joseph B, Pandit V, Aziz H, Vercruysse G, Kulvatunyou N, et al. Increasing trauma deaths in the United States. Ann Surg. 2014;260(1):13-21.

2 Available from: Who.int/ar/news-room/factsheets/detail/road-traffic-injuries.

3 Available from: Stats.gov.sa/ar/258, stats.gov. sa/ar/1009, stats.gov.sa/ar/1020.

4 Available from: Moh.gov.sa/Ministry/Statistics/book/Documents/book-Statistics-2018. pdf.

5 Ansari S, Akhdar F, Mandoorah M, Moutaery K. Causes and effects of road traffic accidents in Saudi Arabia. Public Health. 2000 Jan; 114(1):37-9.

6 Al-Naami MY, Arafah MA, Al-Ibrahim FS. Trauma care systems in Saudi Arabia: an agenda for action. Ann Saudi Med. 2010 JanFeb;30(1):50-8.

7 Alghnam S, Alkelya M, Aldahnim M, Aljerian N, Albabtain I, Alsayari A, et al. Healthcare costs of road injuries in Saudi Arabia: a quantile regression analysis. Accid Anal Prev. 2021 Jul 2;159:106266.

8 Celso B, Tepas J, Langland-Orban B, Pracht E, Papa L, Lottenberg L, et al. A systematic review and meta-analysis comparing outcome of severely injured patients treated in trauma centers following the establishment of trauma systems. J Trauma. 2006 Feb;60(2):371-8; discussion 378

9 Chiara O, Cimbanassi S, Pitidis A, Vesconi S. Preventable trauma deaths: from panel review to population based-studies. World J Emerg Surg. 2006 Apr 11;1:12.

10 Juillard CJ, Mock C, Goosen J, Joshipura M, Civil I. Establishing the evidence base for trauma quality improvement: a collaborative WHO-IATSIC review. World J Surg. 2009 May;33(5):1075-86.

11 Carr BG, Geiger J, McWilliams N, Reilly PM, Wiebe DJ. Impact of adding Level II and III trauma centers on volume and disease severity at a nearby Level I trauma center. J Trauma Acute Care Surg. 2014;77:764-8.

12 Caputo LM, Salottolo KM, Slone DS, Mains CW, Bar-Or D. The relationship between patient volume and mortality in American trauma centres: a systematic review of the evidence. Injury. 2014;45:478-86.

13 Bennett KM, Vaslef S, Pappas TN, Scarborough JE. The volume-outcomes relationship for United States level I trauma centers. J Surg Res. 2011;167:19-23.

14 Marx WH, Simon R, O’Neill P, Shapiro MJ, Cooper AC, Farrell LS, et al. The relationship between annual hospital volume of trauma patients and in-hospital mortality in New York State. J Trauma. 2011;71:339-45.
15 Demetriades D, Martin M, Salim A, Rhee P, Brown C, Chan L. The effect of trauma center designation and trauma volume on outcome in specific severe injuries. Ann Surg. 2005; 242:512-9.

16 Glance LG, Osler TM, Dick A, Mukamel D. The relation between trauma center outcome and volume in the National Trauma Databank. J Trauma. 2004;56:682-90.

17 Marcin JP, Romano PS. Impact of betweenhospital volume and within-hospital volume on mortality and readmission rates for trauma patients in California. Crit Care Med. 2004;32:1477-83.

18 American College of Surgeons Committee on Trauma. Resources for the optimal care of the injured patient. Chicago, IL: American College of Surgeons; 2014.

19 Alharbi RJ, Lewis V, Mosley I, Miller M. Current trauma care system in Saudi Arabia: a scoping literature review. Accid Anal Prev. 2020;144.

20 Available from: Stats.gov.sa/ar/3465.

21 Saudi Red Crescent Authority. Ambulance reports and statistics of the saudi red crescent authority. Saudi Arabia: Saudi Red Crescent Authority. Available from: srca.org.sa/ar.

22 Alghnam S, Alkelya M, Al-Bedah K, Al-Enazi S. Burden of traumatic injuries in Saudi Arabia: lessons from a major trauma registry in Riyadh, Saudi Arabia. Ann Saudi Med. 2014 Jul-Aug;34(4):291-6.

23 Alghnam S, Alkelya M, Alfraidy M, Al-bedah $\mathrm{K}$, Albabtain IT, Alshenqeety O. Outcomes of road traffic injuries before and after the implementation of a camera ticketing system: a retrospective study from a large trauma center in Saudi Arabia. Ann Saudi Med. 2017; 37(1):1-9.

24 Available from: Mot.gov.sa/ar/AboutUs/Pages/MinistryInitiatives.aspx.

25 Al-Ghamdi AS. Emergency medical service rescue times in Riyadh. Accid Anal Prev. 2002 Jul;34(4):499-505.

26 Available from: cbahi.gov.sa/english/accreditation-programs.

27 Available from: Scfhs.org.sa/MESPS/Pages/ statistics.aspx.

28 Alghnam S, Palta M, Hamedani A, Remington PL, Alkelya M, Albedah K, et al. In-hospital mortality among patients injured in motor vehicle crashes in a Saudi Arabian hospital relative to large US trauma centers. Inj Epidemiol. 2014;1(1):1-9.

29 Alharbi R, Miller C, Lewis V. Protocol for a feasibility exploratory multicentre study of factors influencing trauma patients' outcomes of traffic crashes in Saudi Arabia. BMJ Open. 2019;9(10):e032046.
30 Alanazi F, Hussain SA, Mandil A, Alamro N. Towards an electronic national injury surveillance system in Saudi Arabia. East Mediterr Health J. 2015;21(2):140-6.

31 Ford JE, Alqahtani AS, Abuzinada SAA, Cameron PA, Fitzgerald MC, Alenizi AS, et al. Experience gained from the implementation of the Saudi TraumA Registry (STAR). BMC Health Serv Res. 2020 Jan 6;20(1 18):18.

32 Ciesla DJ, Tepas JJ 3rd, Pracht EE, LanglandOrban B, Cha JY, Flint LM. Fifteen-year trauma system performance analysis demonstrates optimal coverage for most severely injured patients and identifies a vulnerable population. J Am Coll Surg. 2013;216(4):6878 .

33 Ashley DW, Pracht EE, Medeiros RS, Atkins EV, NeSmith EG, Johns TJ, et al. An analysis of the effectiveness of a state trauma system: treatment at designated trauma centers is associated with an increased probability of survival. J Trauma Acute Care Surg. 2015;78(4): 706-4.

34 Branas CC, MacKenzie EJ, Williams JC, Schwab CW, Teter HM, Flanigan MC, et al. Access to trauma centers in the United States. JAMA. 2005 Jun 1;293(21):2626-33.

35 Hashmi ZG, Jarman MP, Uribe-Leitz T, Goralnick E, Newgard CD, Salim A, et al. Access delayed is access denied: relationship between access to trauma center care and pre-hospital death. J Am Coll Surg. 2019;228:9-20.

36 Cameron PA, Gabbe BJ, Cooper DJ, Walker T, Judson R, McNeil J. A statewide system of trauma care in Victoria: effect on patient survival. Med J Aust. 2008 Nov 17;189(10):54650.

37 Available from: Facs.org/quality-programs/ trauma/tqp/center-programs/ntdb/ntds/data-dictionary.

38 Horst MA, Gross BW, Cook AD, Osler TM, Bradburn EH, Rogers FB. A novel approach to optimal placement of new trauma centers within an existing trauma system using geospatial mapping. J Trauma Acute Care Surg. 2017 Oct;83(4):705-10.

39 Ciesla DJ, Pracht EE, Cha JY, Langland-Orban B. Geographic distribution of severely injured patients: implications for trauma system development. J Trauma Acute Care Surg. 2012;73(3):618-24

40 Hsia R, Shen YC. Possible geographical barriers to trauma center access for vulnerable patients in the United States: an analysis of urban and rural communities. Arch Surg. 2011; 146(1):46-52. 